\title{
Reinspecting the Climate-Crop Yields Relationship at a Finer Scale and the Climate Damage Evaluation: Evidence from China
}

\author{
Yongbin Zhu, ${ }^{1,2}$ Yajuan Shi, ${ }^{3}$ Changxin Liu, ${ }^{1,2}$ Bing Lyu $\left(\mathbb{D},{ }^{4}\right.$ and Zhenbo Wang ${ }^{5}{ }^{5}$ \\ ${ }^{1}$ Institutes of Science and Development, CAS, Beijing 100190, China \\ ${ }^{2}$ School of Public Policy and Management, University of CAS, Beijing 100190, China \\ ${ }^{3}$ Beijing City University, Beijing 100083, China \\ ${ }^{4}$ College of Tourism and Geography, Yunnan Normal University, Kunming 650050, China \\ ${ }^{5}$ Institute of Geographic Sciences and Natural Resources Research, CAS, Beijing 100190, China \\ Correspondence should be addressed to Bing Lyu; 601630892@qq.com and Zhenbo Wang; wangzb@igsnrr.ac.cn
}

Received 18 May 2020; Revised 28 June 2020; Accepted 14 July 2020; Published 17 September 2020

Guest Editor: Jun Yang

Copyright ( $\odot 2020$ Yongbin Zhu et al. This is an open access article distributed under the Creative Commons Attribution License, which permits unrestricted use, distribution, and reproduction in any medium, provided the original work is properly cited.

\begin{abstract}
This paper reinvestigated the climate-crop yield relationship with the statistical model at crops' growing stage scale. Compared to previous studies, our model introduced monthly climate variables in the production function of crops, which enables separating the yield changes induced by climate change and those caused by inputs variation and technique progress, as well as examining different climate effects during each growing stage of crops. By applying the fixed effect regression model with province-level panel data of crop yields, agricultural inputs, and the monthly climate variables of temperature and precipitation from 1985 to 2015 , we found that the effects of temperature generally are negative and those of precipitation generally are positive, but they vary among different growth stages for each crop. Specifically, GDDs (i.e., growing degree days) have negative effects on spring maize's yield except for the sowing and ripening stages; the effects of precipitation are negative in September for summer maize. Precipitation in December and the next April is significantly harmful to the yield of winter wheat; while, for the spring wheat, GDDs have positive effects during April and May, and precipitation has negative effects during the ripening period. In addition, we computed climateinduced losses based on the climate-crop yield relationship, which demonstrated a strong tendency for increasing yield losses for all crops, with large interannual fluctuations. Comparatively, the long-term climate effects on yields of spring maize, summer maize, and spring wheat are more noticeable than those of winter wheat.
\end{abstract}

\section{Introduction}

The ongoing human interference with the climate system poses many risks for human and natural systems [1]. With growing evidence suggesting that continuous accumulation of greenhouse gases in the atmosphere is leading to global warming, the climate-crop yield relation has drawn increasing attention since agriculture is one of the most climate-sensitive sectors.

The widely used process-based approach emulates the main processes of crop growth, which are typically developed and tested using experimental trials and thus offer the distinct advantage of leveraging decades of research in crop physiology and reproduction, agronomy, and soil science, among other disciplines [2]. However, as argued by [3], the potential weaknesses of process-based approaches are their complexity, uncertainty about the structure of the physiological process, and the large number of parameters. Some agronomists seem to worry about possible misspecification and omitted variables biases [4-6].

Statistical models provide an alternative to processbased models, which merely use historical data to calibrate a limited number of parameters with relatively simple regression models. Lobell and Field [7] demonstrated the negative impacts of climate trends on crop yields at the global scale by constructing an empirical relationship between averaged global yields of six major crops and the spatially aggregated temperatures and precipitation during the growing seasons. Schilenker and Lobell [8] provided some statistical evidence for how the yields of five 
staple crops in Africa relate to weather fluctuations using a country-level panel dataset and concluded that the mean estimates of aggregate production changes are $-22,-17$, $-17,-18$, and $-8 \%$ for maize, sorghum, millet, groundnut, and cassava, respectively. At provincial scales, Tao et al. [9] investigated the climate-crop yield relationships and found that maize was the most vulnerable to the trends in monthly fields of both maximum temperature $\left(T_{\mathrm{m}}\right)$ and minimum temperature $\left(T_{\mathrm{n}}\right)$, while rice, wheat, and soybean were affected more by $T_{\mathrm{n}}$ than by $T_{\mathrm{m}}$. Chen and Tian [10] examined the responses of rice yields to weather variations in China and discovered that rising daily minimum temperature increased but precipitation reduced early and late rice yields in China. Schilenker and Lobell $[3,11]$ and Chen et al. [12] studied the nonlinear effects of weather on crop yields and the impacts of climate change on agriculture at a finer county scale. In their studies, they found the inverted U-shape between yield and climate variables, based on which they derived the optimal climate conditions for the crops. The authors in $[13,14]$ also tried to unpack the climate drivers of agricultural yields with statistical models. The former study found that the largest drivers of yield loss were freezing temperatures in the fall and extreme heat events in the spring; the latter argued that exposure to relatively high temperature $\left(>30^{\circ} \mathrm{C}\right)$ over warmer parts of the growing season and exposure to relatively cool temperatures appeared detrimental to most crops.

Methodologically, these studies have taken broad aggregate weather/climate measures during entire growing seasons as independent variables, which is incapable of reflecting the distinct climate conditions required by crops during different growing stages. Liu et al. [15] and Wang et al. [16] evaluated the effects of climate factors in spring, summer, autumn, and winter on the agricultural net revenue/output, but the four seasons often do not correspond to crop growing seasons. Butler and Huybers [17] studied the sensitivity of maize yield to extreme temperatures in four growth phases and found that temperature sensitivity peaked during silking and grain-filling on average. Butler et al. [18] further brought six distinct growing stages and concluded that temperature sensitivity varied greatly over the course of crop development and yield sensitivity to GDDs (i.e., growing degree days) and KDDs (i.e., killing degree days) varied across vegetative, early, and late grain-filling growth phases.

On the other hand, many studies tend to build the climate-crop yield relationship without considering the management effects. Chen and Tian [10] investigated the responses of early rice, middle-season rice, and late rice yields to weather variations in China without considering the management effects. Lobell et al. [19] included a time trend variable in the empirical relationship between yearto-year variations in weather and yield to ensure that the regression is not biased from common trends in the data, but it still ignored the management effects. Some other studies extracted the yield fluctuation from the long-term yields growth trend, deeming the former as induced by climate change and the latter as caused by technological advances. For instance, Fang et al. [20] estimated the climate-crop yield relationship by regressing the fluctuated yield with the climate factors; Lobell and Field [7] and Tao et al. [9] studied the relationship between the first difference time series for yield and climate assuming that the confounding influence of long-term variation would be avoided; Schilenker and Lobell [8], Gammans et al. [21], and Ortiz-Bobea et al. [13] included a quadratic time trend to capture overall technological progress. However, these studies have all eliminated the effect of primary input, e.g., fertilizer on yields.

This study attempts to differentiate the effects of management and climate change on the crop yield. Moreover, we reinspect the climate-crop yields relationship at a finer scale to reflect the important climate factors during different growing stages. In this paper, we selected a production function as the basic model and then introduced the climate variables. This treatment enables us to distinguish yield changes caused by variations of physical inputs or weather conditions. Besides, we expanded the climate measures into monthly variables, which enables us to discern the crucial climate variables corresponding to each growth stage, rather than the aggregate climate variables for the whole growing season. Finally, these climate-crop yield relationships support a specific functional form to estimate the climate-induced losses.

\section{Methods and Data}

2.1. Basic Model. In order to distinguish the yield variation caused by climate factors from those which result from technology or physical input change, we developed a climate-yield relationship based on the crop's production function. Production function is an economic concept that refers to the technological relation between physical inputs and outputs of the goods, which is typically used to reflect how the inputs of all factors transform to the output. As to the agriculture sector, the crop yield can be generally taken as the output indicator, and the input factors include soil land, agricultural labor, fertilizer, machinery, and irrigation. It is observed that the crop yield may not be solely affected by climate factors but also determined by the physical inputs. Hence, the production function serves to reflect the second part of variation. Here, we take the reduced Cobb-Douglas form of production function, which is given as

$$
y=A \cdot x_{1}^{\alpha_{1}} \cdot x_{2}^{\alpha_{2}} \cdot x_{3}^{\alpha_{3}} \cdots=A \cdot \prod_{i=1}^{p} x_{i}^{\alpha_{i}},
$$

where $y$ denotes crop yields per unit area and $x_{\mathrm{i}}$ represents each physical input, e.g., fertilizer, machinery, or irrigation, with $\alpha$ denoting the output elasticity for each input, i.e., the percentage change of crop yield induced by the percentage change of certain input. A is the region-specific total factor productivity (TFP). If we take the log form of the former production function, we will deduce the linearized statistical regression model: 


$$
y^{\prime}=a+\alpha_{1} x_{1}^{\prime}+\alpha_{2} x_{2}^{\prime}+\alpha_{3} x_{3}^{\prime}+\cdots+\varepsilon=a+\sum_{i=1}^{p} \alpha_{i} x_{i}^{\prime}+\varepsilon,
$$

where $y^{\prime}=\log (y), a=\log (A), x \prime=\log (x)$, and $\varepsilon$ is the error term; a represents the province-level fixed effects that are unique to each province but are time-invariant, e.g., the soil property, crop varieties, and cultivation and management traditions.

Under this framework, we introduce climate factors into (2). To discern the key climate variables corresponding to the crops' growing seasons, we add into (2) the monthly temperature and precipitation variables, rather than the aggregate temperature and precipitation variables for the entire growing season. Thus, we get

$$
y^{\prime}=a+\sum_{i=1}^{p} \alpha_{i} x_{i}^{\prime}+\sum_{m}\left(\theta_{m} T_{i t}^{(m)}+\phi_{m} P_{i t}^{(m)}\right)+\varepsilon .
$$

In (3), the monthly temperature and precipitation variables are $T$ and $P$, respectively, and $m$ denotes each month in the growing season. $\theta$ and $\phi$ are parameters that reflect the responses of crop yields to temperature and precipitation variation for the corresponding month in the growing seasons.

Given the linear specification of regression model (3), $\theta$ and $\phi$ can be interpreted as the effects on crop yields of per unit change in the climate variables. Taking the exponential form of (3) produces the following form:

$$
y=A \cdot \exp \left[\sum_{m}\left(\theta_{m} T^{(m)}+\phi_{m} P^{(m)}\right)\right] \cdot f^{\alpha} \cdot m^{\beta} .
$$

The exponential part in (4) can be deemed as the climate effects on crop productivity (or the crop's TFP). If we let

$$
A^{\prime}=A \cdot \Omega=A \cdot \exp \left[\sum_{m}\left(\theta_{m} T^{(m)}+\phi_{m} P^{(m)}\right)\right],
$$

then, the climate-induced loss of crop yields through productivity decline will be

$$
L=\frac{1-\Omega}{\bar{\Omega}}=1-\exp \left[\sum\left(\theta_{m}\left(T^{(m)}-\bar{T}^{(m)}\right)+\phi_{m}\left(P^{(m)}-\bar{P}^{(m)}\right)\right)\right],
$$

where $L$ is the loss of crop yields due to climate deviating from the perennial average value.

2.2. Data Collection. This study applies the fixed effect regression model with province-level panel data to reinspect the climate-crop yields relationship in China. We collected the province-level production and planted acres for maize and wheat as well as the agricultural inputs, i.e., fertilizer and machinery, from the National Bureau of Statistics (NBS) for the years 1985-2015. The crop yields were computed as total crop production in a province divided by the acres planted in that province. The NBS provided separate statistics for winter wheat and spring wheat but not for maize. Therefore, we divided maize into spring and summer maize by its production areas.

As for the temperature and precipitation data, we collected them from $\mathrm{Wu}$ et al. [22], which produced gridded daily scale dataset CN05.1 at a resolution of $0.25^{\circ}$ latitude by $0.25^{\circ}$ longitude. We then aggregated the temperature and precipitation data into province-level data using cropland area as the weighting function. The next step was to aggregate the daily climate data into monthly data at the provincial scale. Growing degree days (GDDs), which are defined as the sum of truncated degrees between two boundaries, are typically used to model the impact of temperature; for example, the studies in $[23,24]$ suggest the bounds of $8^{\circ} \mathrm{C}$ and $32^{\circ} \mathrm{C}$ for maize and of $5^{\circ} \mathrm{C}$ and $32^{\circ} \mathrm{C}$ for wheat; but the growth of crops ceases when the temperature goes out of the according boundaries. We then utilized the daily mean temperature to compute the GDDs over each month and obtained the cumulated precipitation for each month.

\section{Climate Effect}

We considered six different model specifications in our empirical analysis by adding the climate variables progressively. Specifically, Model 1 is the basic production function that merely reserves the significant physical inputs. We then included the monthly GDDs in Model 2 and the monthly precipitation in Model 3 separately to discern the key influential climate variables. Model 4 added all climate variables simultaneously to examine the aggregate effects of climate on crop yields, in which some original significant variables turn out to be insignificant due to multicollinearity. Thus, Model 5 applied the stepwise regression to remove all insignificant variables in Model 4. However, Model 5 inevitably dropped some key climate variables that are originally identified to be significant in Model 2 or Model 3. In order to reserve all influential climate factors, Model 6 employed the principal component analysis (PCA) approach to eliminate the multicollinearity issue and meanwhile keep all of the significant climate variables in Model 2 and Model 3. Furthermore, Model 6 was used to calculate the climate-induced losses.

The monthly climate effects on crop yield are totally different since the four crops have distinct corresponding growth seasons. The sowing date of spring maize in China is April $10^{\text {th }}$ at the earliest and May $11^{\text {th }}$ at the latest; its ripening period is from September $1^{\text {st }}$ to $27^{\text {th }}$. Summer maize is generally sown between May $10^{\text {th }}$ and June $21^{\text {st }}$ and harvested between August $21^{\text {st }}$ and October $2^{\text {nd }}$. Sowing winter wheat begins in mid-to-late September and continues until early October in China, and, by the end of next May or late June, the wheat enters a mature stage. Therefore, the growing season of winter wheat lasts 230-270 days from September to June of the following year. The winter wheat ceases growing when the mean temperature drops to $2^{\circ} \mathrm{C}$; and, after the mean temperature increases and stabilizes to a level above $0^{\circ} \mathrm{C}$, it resumes growing until the next year. Spring wheat has a relatively short period of duration, approximately 90 days. It is sown in spring and harvested in autumn with its growing season lasting from March to July, which is suitable for the cold areas in the northern China. Table 1, therefore, 
TAвLE 1: Summary of the climate-yield relationship for maize and wheat in China.

\begin{tabular}{|c|c|c|c|c|c|c|c|c|c|c|c|c|c|}
\hline Crops & Climate variables & Jan. & Feb. & Mar. & Apr. & May & Jun. & Jul. & Aug. & Sep. & Oct. & Nov. & Dec. \\
\hline \multirow{2}{*}{ Spring maize } & GDDs & & & & $(+)$ & $(-)$ & $(-)$ & $(-)$ & $(-)$ & + & & & \\
\hline & Prec. & & & & + & + & $(+)$ & $(+)$ & + & + & & & \\
\hline \multirow{2}{*}{ Summer maize } & GDDs & & & & & $(-)$ & - & $(-)$ & - & - & & & \\
\hline & Prec. & & & & & + & $(+)$ & $(+)$ & + & $(-)$ & & & \\
\hline \multirow{2}{*}{ Winter wheat } & GDDs & $(-)$ & - & - & + & - & + & & & $(-)$ & + & - & + \\
\hline & Prec. & - & + & + & $(-)$ & + & - & & & $(+)$ & $(+)$ & + & $(-)$ \\
\hline \multirow{2}{*}{ Spring wheat } & GDDs & & & - & + & + & $(-)$ & - & & & & & \\
\hline & Prec. & & & + & + & $(+)$ & + & - & & & & & \\
\hline
\end{tabular}

summarizes the estimation results of climate-yield relationships for maize and wheat in China (referring to SI for detailed regression results).

The estimation for spring maize (Table S1) indicates that all GDDs during the growing season except in September (the ripening season) affect the yield significantly, probably because spring maize has entered its ripening season by September. Specifically, high GDDs in April (sowing period) promote yield but high GDDs in all other months lead to yield decline. Spring maize distributes mainly in the cold north region where temperature is low in April, which is unfavorable for seed emergence. Warming temperature in April will promote the crop's growth and its yield. However, these regions enter into summer soon after May and the temperature rises to a high level quickly. High temperature is usually accompanied by drought which affects the jointing, earing, and flowering pollination [25]. Thus, high temperature in May to August plays a significantly negative role in yield increase of spring maize.

Precipitation generally has a positive effect on spring maize yield during the entire growing season. While statistically the effects are significant for June and July, this is partly because spring maize is in the fast growth period during June-July, and the water requirement of crops reaches its highest peak. On the other hand, the rapid rise in temperature exacerbates the drought condition, which adversely influences the dry matter synthesis and grouting. Therefore, precipitations at this stage will satisfy the crop's water demand, alleviate the drought condition, and increase its yield.

The GDDs have negative effects on summer maize yield for the entire growing season (Table S2), with the effects of GDDs in May and July being statistically significant. Summer maize is mainly sown directly after wheat harvest in late May when the temperature has risen up. The continuous high temperature will cause periodic droughts. In May, the emergence of summer maize is sensitive to water in the sowing stage; and higher temperature will affect the seeding emergence indirectly, while, for the stage of jointing and booting in July, too high a temperature will make pollen inactivated and thus influence its pollination. Besides, maize in this period requires the maximum water; and thus higher temperature will affect its growth indirectly as well.

Precipitation has positive effects except for September, the ripening season, while, statistically, the rainfall in June and July plays a very important role in boosting the yields since during that period the water demand is large. On the contrary, massive precipitation in the ripening period may cause a reduction in yield, for that rainy and cloudy weather affects photosynthesis and the accumulation of organic matter, which is easy to cause greediness and late ripening [25].

While, for the winter wheat, the GDDs in September and January have significant negative effects on its yields (Table S3), September is still the hot time of the year and the adverse effect of heat on winter wheat in sowing period is obvious. Otherwise, previous studies [26-29] have indicated that higher temperature in the sowing period leads to excessive growth of wheat seedlings that are prone to damage from freezing, pests, and disease due to less accumulation of nutrition. In addition, winter wheat has to experience a period of cold conditions to finish vernalisation. Therefore, higher temperature during the wintering period is not good for its growth and may cause yield decline. Other studies [30-32] have showed that cool weather in fruit-developing stage is beneficial to increase the grain weight of winter wheat and high temperature during that period will cause damage to its yield. Our estimation finds the same result that high temperature in May, the grouting stage of winter wheat, adversely affects its yield, but this effect is not significant statistically.

On the other hand, precipitation in the period of emergence (Sep. to Oct.) helps the winter wheat sprout and tiller, leading to a full stand and a strong seedling, which has positive effects on the yields. However, excessive precipitation in December and April of the next year has adverse effects on its yield, but with no solid agronomy foundation. Winter wheat experiences a long period of growth, spanning four seasons of autumn, winter, spring, and summer; the yield fluctuates under the influence of meteorological conditions. However, statistically, only a few climate factors have significant effects on its yield.

Since low temperature in the sowing period (March) helps the spring wheat go through the vernalisation stage and ripen in time, the GDDs in March have negative effects on the yield (Table S4), but it is not statistically significant. The estimation also showed that the increased temperature in the sprouting and flowering stage (June) significantly damages the yield of spring wheat. The reason is similar to that of winter wheat, which is because high temperature will damage the grouting of spring wheat and thus decrease its yield [33-35]. For precipitation, spring wheat benefits from it for all growth stages except the ripening stage. But, statistically, only that in June plays a significant role in the yield, which indicates that an increase in rainfall during the 
jointing and sprouting stage benefits the growth of spring wheat and, hence, promotes its yield; nevertheless, rainfall in July, the filling stage, may lead to unsaturated grains and thus causes yield decline, although this effect is not significant.

\section{Estimate of Climate-Induced Losses}

With the climate-yield relationship, we computed the climate-induced losses for the four crops by bringing the actual monthly anomaly of climate variables into (6).

Taking the average monthly GDDs and precipitation during 1985-2015 for each province as references, we calculated the climate anomaly value and obtained the losses caused by local climate change in the past 30 years, as shown in Figure 1.

As seen from Figure 1, the climate-induced yield change fluctuated among years for all crops, but the long-term trends have demonstrated some obvious features. For instance, the negative effects of climate change on the yields were prevalent in the last decades, indicating that the climate-induced losses increased for all crops. Comparatively, the long-term climate effects (red lines in Figure 1) on yields of spring maize, summer maize, and spring wheat are more noticeable than those of winter wheat. In addition, the responses of summer maize and winter wheat to climate change were more sensitive, with many outliers in Figure 1 for the two crops, indicating that the abnormal effects in some planting zones frequently occurred. As these two crops were widely planted in many provinces, the climate effects on yields varied among different planting zones as well.

Compared to the 30 -year average climate factors, i.e., monthly GDDs and precipitations, the weather condition favored yield of spring maize before the year of 1998 and then turned to be detrimental. The turning point of climate effect from positive to negative occurred in 2005 for summer maize and in 1995 for spring wheat, with yield decreases of roughly $10 \%$ over the past 30 years, while the effects on winter wheat yield, which fluctuated around the average level, are negligible.

Meanwhile, Figure 1 displays some exceptional years in which obvious climate damages were observed in most planting areas, reflected in the figure as the main range of the bars located below the horizontal line of zero loss, such as the years of 1994, 1997, 1999-2002, 2005-2007, 2010-2011, and 2015 for spring maize; the years of 1994, 1997, 2000, 2007, 2010, 2012, and 2014 for summer maize; the years of 1994, $1999,2003,2007$, and 2010 for winter wheat; and the years of 1995, 2001-2002, 2005, 2008, and 2011-2014 for spring wheat. However, the climate in the recent few years has reversed the downward trend of damages to the crops of spring maize and winter and spring wheat.

Another feature that is reflected by the height of each box-line is the climate-induced loss disparity among planting areas. The wider the box-line spreads, the larger the disparity among planting areas is. According to Figure 1, large disparities in climate effects occurred in 1991, 1997, and 2000 for spring maize; in 1985, 1994, 1996, and 2002 for summer maize; in 2002 and 2010 for winter wheat; and in
1987, 2009, and 2010 for spring wheat. Since the distribution of spring maize and spring wheat was relatively concentrated and thus their climate conditions were similar, the impacts of climate change were consistent with either yield-increasing effects or yield-decreasing effects. Therefore, the boxes in Figure 1 generally appeared on one side of the horizontal axis for these two crops. On the other hand, the boxes for summer maize and winter wheat crossed the horizontal axis in most years, and thus many outliers existed there. The reason was that the two crops were widely dispersed and faced extremely different climate conditions; therefore, their climate effects varied to a large extent.

\section{Discussion}

Previous studies employing aggregate climate factors, either annual averages of climate variables or the average ones during the growing season for each crop, ignored the distinct climate effects during different growth stages. As a result, this may misspecify the climate-yield relationship since the mean temperatures or precipitation within the growing season can hide the fluctuation of climate factors, and experimental studies have shown that even a few days of temperature above a threshold value, if coincident with some key growing stages, can significantly reduce yield, through affecting subsequent reproductive processes [36].

Hence, some recent studies $[10,15]$ have, to some extent, improved this flaw by including climate variables of various periods as independent variables. Nevertheless, a more detailed and crop-specific division of growth stages supporting the recognition of key climate variables has not appeared in the literature. Our findings presented above are useful for developing effective crop-breeding and climateadaptive measures in China and, at the same time, for filling the gap between climate model and climate feedbacks in time resolution.

Three major limitations or caveats apply. First, the estimates of the climate-yield relationship were based on the province-level panel data. Since considerable heterogeneities exist in crop yields, inputs, and weather conditions within a province, the estimated parameters of climate effects on yields could be larger or smaller than the actual effects. Moreover, this may also be one reason for the absence of a nonlinear relationship as detected by $[3,11]$. The aggregation of data within provinces not only reduced the sample size but also eliminated the detailed information on how climate affects crop yields. Therefore, an improvement of this work would be to reestimate the climate effects at a smaller scale, depending on data availability.

Second, this study failed to reflect the effect of heat stress on crop yield since the temperature data at provincial scale shows that it seldom exceeds the threshold of $32^{\circ} \mathrm{C}$ for most provinces in the past 30 years except for a very few of provinces, e.g., Shanghai, in July or August of some years. So, the variable of GDD32+, which represents the GDDs of over $32^{\circ} \mathrm{C}$, has been removed from the model because of the singular issue. Additionally, in order to test the robustness of our estimates, we further applied the robust and bootstrap techniques, as shown in Tables S5-S8. The 


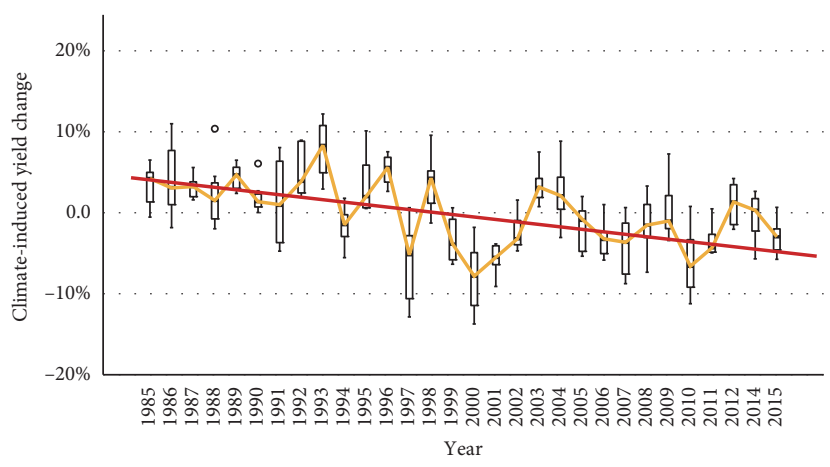

(a)

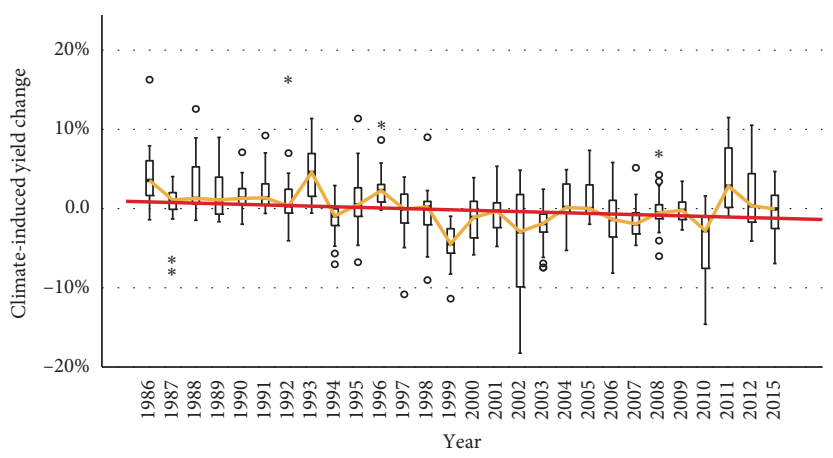

(c)

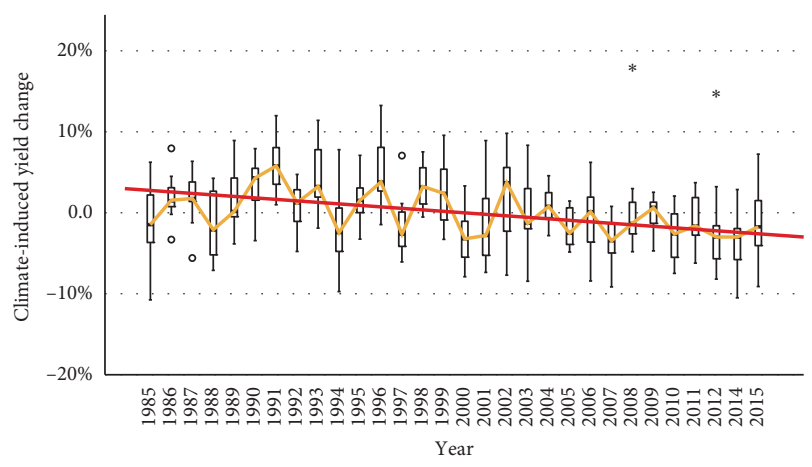

(b)

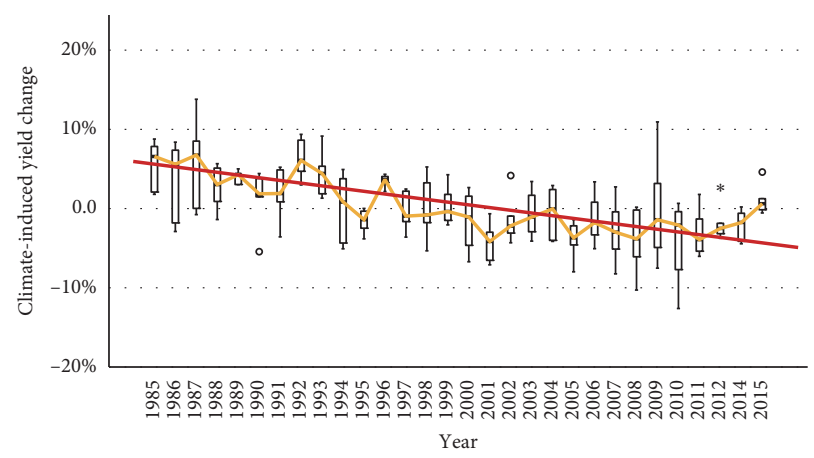

(d)

FIGURE 1: Climate effects on the crop yields of maize and wheat in the past 30 years (1985-2015). The vertical box-and-whisker plots reflect the climate-induced yield change distribution among crop planting zones in each year, with some outliers denoted by circles and stars; the orange lines connect the medians of yield change and the red lines indicate the long-term trend of yield change for each crop. (a) Spring maize. (b) Summer maize. (c) Winter wheat. (d) Spring wheat.

comparisons indicate that our estimates are relatively robust, except for the effects of GDD4 on spring maize and GDD6 on summer maize, GDD10, GDD2, and GDD4 on winter wheat, which become more significant. However, the effects of GDD5, GDD8, and P7 on spring maize and P7 on summer maize become less significant; and the effects of P12 on winter wheat and P6 on spring wheat become insignificant. Nevertheless, we should bear in mind that the estimates only reflect the climate-yield relationships for the last 30 years since a longer period of record on crop input-output lacks.

Third, our model was built on a production function that included only two physical inputs due to poor data access. The climate variables mainly focused on temperature and precipitation effects and did not consider the impacts of radiation and $\mathrm{CO}_{2}$ fertilization, which have been found to have large effects in laboratory studies and may also influence crop yields [37-39]. Despite these limitations, our models have explained more than 70 percent of the crop yields' fluctuations, as indicated by the adjusted $R^{2}$ estimator. Further studies may extend our work by considering more input factors or climate variables.

Moreover, climate factors may have lagging effects on crop yield, while this paper only considers the effects of climate factors within the growing seasons, that is, the direct effects. Besides, given the nature of the dataset, the model estimates may be influenced by spatial or temporal autocorrelations, although we have considered the autocorrelations between temperature and precipitation within each month.

\section{Conclusions}

In contrast to previous work $[7,8,10]$ that takes broad aggregate weather/climate measures during entire growing seasons as independent variables, we found that the effects of temperature and precipitation vary among different growth stages for each crop. Specifically, GDDs have negative effects on spring maize's yield for nearly the entire growing season, except for the sowing and ripening stages, and the effects of GDDs on summer maize are all negative. Both spring and summer maize benefit from rainfall; the effects of precipitation on maize yield are consistently positive, with September being an exception for summer maize.

Winter wheat has a longer growing season relative to other crops, so the climate effects become more complicated: GDDs in the sowing (Sep.) and wintering (Jan.) periods have significant negative effects; precipitation in Sep. and Oct. is beneficial, but, in Dec. and Apr. of the next year, it is significantly harmful to the yield. As for the spring wheat, GDDs have negative effects except during Apr. and May; precipitation has positive effects except for the ripening 
period. Only GDDs in Jun. and precipitation in May have significant impacts on spring wheat's yield.

Our findings on climate-induced losses revealed that the climate change during the past three decades has caused a prominent trend of increasing losses for these crops except for winter wheat. The interannual fluctuation of climateinduced losses varied between crops, being more apparent for spring maize than for the other crops. The disparity of climate-induced losses among planting zones was larger for summer maize and winter wheat since the two crops are distributed more widely in China and thus experienced very distinct climate conditions.

\section{Data Availability}

The agriculture input data are drawn from the NBSC repository (www.stats.gov.cn); The climate data are available from the corresponding author upon request.

\section{Conflicts of Interest}

The authors declare that they have no conflicts of interest.

\section{Acknowledgments}

This work was financially supported by the National Basic Research Program of China (Grant no. 2016YFA0602700).

\section{Supplementary Materials}

Table S1: estimation of the climate-yield relationship for spring maize. Table S2: estimation of the climate-yield relationship for summer maize. Table S3: estimation of the climate-yield relationship for winter wheat. Table S4: estimation of the climate-yield relationship for spring wheat. Table S5: comparison with the robust estimates of climateyield relationship for spring maize. Table S6: comparison with the robust estimates of climate-yield relationship for summer maize. Table S7: comparison with the robust estimates of climate-yield relationship for winter wheat. Table S8: comparison with the robust estimates of climate-yield relationship for spring wheat. (Supplementary Materials)

\section{References}

[1] IPCC, "Summary for policymakers," in IPCC, Climate Change 2014: Impacts, Adaptation, and Vulnerability, Cambridge University Press, Cambridge, NY, USA, 2014.

[2] D. B. Lobell and M. B. Burke, "On the use of statistical models to predict crop yield responses to climate change," Agricultural and Forest Meteorology, vol. 150, no. 11, pp. 1443-1452, 2010.

[3] W. Schlenker and M. J. Roberts, "Nonlinear temperature effects indicate severe damages to U.S. crop yields under climate change," Proceedings of the National Academy of Sciences, vol. 106, no. 37, pp. 15594-15598, 2009.

[4] S. P. Long, E. A. Ainsworth, A. D. B. Leakey, and P. B. Morgan, "Global food insecurity. Treatment of major food crops with elevated carbon dioxide or ozone under large-scale fully openair conditions suggests recent models may have overestimated future yields," Philosophical Transactions of the Royal Society B: Biological Sciences, vol. 360, no. 1463, pp. 2011-2020, 2005.

[5] T. R. Sinclair and N. a. G. Seligman, "Crop modeling: from infancy to maturity," Agronomy Journal, vol. 88, no. 5, pp. 698-704, 1996.

[6] T. R. Sinclair and N. a. Seligman, "Criteria for publishing papers on crop modeling," Field Crops Research, vol. 68, no. 3, pp. 165-172, 2000.

[7] D. B. Lobell and C. B. Field, "Global scale climate-crop yield relationships and the impacts of recent warming," Environmental Research Letters, vol. 2, no. 1, Article ID 014002, 2007.

[8] W. Schilenker and D. B. Lobell, "Robust negative impacts of climate change on African agriculture," Environmental Research Letters, vol. 5, Article ID 014010, 2010

[9] F. Tao, M. Yokozawa, J. Liu, and Z. Zhang, "Climate-crop yield relationships at provincial scales in China and the impacts of recent climate trends," Climate Research, vol. 38, pp. 83-94, 2008.

[10] X. Chen and G. Tian, "Impacts of weather variations on rice yields in China based on province-level data," Regional Environmental Change, vol. 16, no. 7, pp. 2155-2162, 2016.

[11] W. Schlenker and M. J. Roberts, "Nonlinear effects of weather on corn yields," Review of Agricultural Economics, vol. 28, no. 3, pp. 391-398, 2006.

[12] S. Chen, X. Chen, and J. Xu, "Impacts of climate change on agriculture: evidence from China," Journal of Environmental Economics and Management, vol. 76, no. 8, pp. 105-124, 2016.

[13] A. Ortiz-Bobea, H. Wang, C. M. Carrillo, and T. R. Ault, "Unpacking the climatic drivers of US agricultural yields," Environmental Research Letters, vol. 14, no. 6, Article ID 064003, 2019.

[14] J. Tack, A. Barkley, and L. L. Nalley, "Effect of warming temperatures on US wheat yields," Proceedings of the National Academy of Sciences, vol. 112, no. 22, pp. 6931-6936, 2015.

[15] H. Liu, X. Li, G. Fischer, and L. Sun, "Study on the impacts of climate change on China's agriculture," Climatic Change, vol. 65, no. 1-2, pp. 125-148, 2004.

[16] J. Wang, R. Mendelsohn, A. Dinar, J. Huang, and S. L. Rozelle, "The impact of climate change on China's agriculture," Agricultural Economics, vol. 40, no. 3, pp. 323-337, 2009.

[17] E. Butler and P. Huybers, "Variations in the sensitivity of US maize yield to extreme temperatures by region and growth phase," Environmental Research Letters, vol. 10, no. 3, Article ID 034009, 2015.

[18] E. E. Butler, N. D. Mueller, and P. Huybers, "Peculiarly pleasant weather for US maize," Proceedings of the National Academy of Sciences, vol. 115, no. 47, pp. 11935-11940, 2018.

[19] D. B. Lobell, W. Schlenker, and J. Costa-Roberts, "Climate trends and global crop production since 1980," Science, vol. 333, no. 6042, pp. 616-620, 2011.

[20] X. Fang, Y. Wang, T. Xu, and Y. Yun, "Contribution of climate warming to rice yield in Heilongjiang province," Acta Geographica Sinica, vol. 59, no. 6, pp. 820-828, 2004, in Chinese.

[21] M. Gammans, P. Mérel, and A. Ortiz-Bobea, "Negative impacts of climate change on cereal yields: statistical evidence from France," Environmental Research Letters, vol. 12, no. 5, Article ID 054007, 2017.

[22] J. Wu, X. Gao, F. Giorgi, and D. Chen, "Changes of effective temperature and cold/hot days in late decades over China based on a high resolution gridded observation dataset," International Journal of Climatology, vol. 37, pp. 788-800, 2017. 
[23] J. T. Ritchie and D. S. NeSmith, "Temperature and crop development," in Modeling Plant and Soil Systems. Agronomy Monograph 31, J. Hanks and J. T. Richie, Eds., American Society of Agronomy, Madison WI, USA, 1991.

[24] W. Schlenker, W. M. Hanemann, and A. C. Fisher, "The impact of global warming on U.S. agriculture: an econometric analysis of optimal growing conditions," Review of Economics and Statistics, vol. 88, no. 1, pp. 113-125, 2006.

[25] Y. Ma, Z. Wang, Q. Luan, L. Hu, and A. Zhang, "Relation between maize yield and eco-climate factors," Chinese Journal of Agrometeorology, vol. 30, no. 4, pp. 565-568, 2009, in Chinese.

[26] Q. Gao, X. Xue, Y. Liang, Y. Wu, and Z Ru, "Studies on regulating sowing time of wheat under the warm winter conditions," Journal of Triticeae Crops, vol. 22, no. 2, pp. 46-50, 2002, in Chinese.

[27] X. Li, D. Zhang, H. Wang et al., "Impact of temperature increment before the over-wintering period on growth and development and grain yield of winter wheat," Chinese Journal of Applied Ecology, vol. 26, no. 3, pp. 839-846, 2015, in Chinese.

[28] X. Song, W. Huang, B. Cui, and J. Zhou, "Winter wheat seedtime monitoring through satellite remote sensing data," in Computer and Computing Technologies in Agriculture V. CCTA 2011. IFIP Advances in Information and Communication Technology, D. Li and Y. Chen, Eds., Springer, Berlin, Germany, 2012.

[29] G. Zhao, X. Chang, Y. Yang, Z. Li, G. Yu, and H. Li, "Study on high-yield, high-efficiency and adapting cultivating technology in winter wheat," Journal of Triticeae Crops, vol. 29, no. 4, pp. 690-695, 2009, in Chinese.

[30] K. Tan, S. Fang, and S. Ren, "Experiment study of winter wheat growth and yield response to climate warming," Acta Meteorologica Sinica, vol. 70, no. 4, pp. 902-908, 2012, in Chinese.

[31] K. Tan, X. Yang, S. Ren, and S. Fang, "Impact of high temperature stress at the grain-filling stage on winter wheat yield," Acta Ecologica Sinica, vol. 35, no. 19, pp. 6355-6361, 2015, in Chinese.

[32] G. Xia, J. Cui, T. Guo, and C. Wang, "Study on relationship between temperature and the grain weight in the grain filling period of winter wheat," Journal of Henan Agricultural University, vol. 37, no. 3, pp. 213-216, 2003, in Chinese.

[33] M. T. Labuschagne, O. Elago, and E. Koen, "The influence of temperature extremes on some quality and starch characteristics in bread, biscuit and durum wheat," Journal of Cereal Science, vol. 49, no. 2, pp. 184-189, 2009.

[34] T. Majoul-Haddad, E. Bancel, P. Martre, E. Triboi, and G. Branlard, "Effect of short heat shocks applied during grain development on wheat (Triticum aestivum L.) grain proteome," Journal of Cereal Science, vol. 57, no. 3, pp. 486-495, 2013.

[35] D. J. Skylas, S. J. Cordwell, P. G. Hains et al., "Heat shock of wheat during grain filling: proteins associated with heattolerance," Journal of Cereal Science, vol. 35, no. 2, pp. 175$188,2002$.

[36] T. R. Zhang, P. Q. Craufurd, R. H. Ellis, J. R. Porter, and P. V. Vara Prasad, "Temperature variability and the yield of annual crops," Agriculture, Ecosystems \& Environment, vol. 82, no. 1-3, pp. 159-167, 2000.

[37] A. D. B. Leakey, E. A. Ainsworth, C. J. Bernacchi, A. Rogers, S. P. Long, and D. R. Ort, "Elevated $\mathrm{CO}_{2}$ effects on plant carbon, nitrogen, and water relations: six important lessons from FACE," Journal of Experimental Botany, vol. 60, no. 10, pp. 2859-2876, 2009.

[38] S. P. Long, E. A. Ainsworth, A. D. B. Leakey, J. Nösberger, and D. R. Ort, "Food for thought: lower-than-expected crop yield stimulation with rising $\mathrm{CO}_{2}$ concentrations," Science, vol. 312, no. 5782, pp. 1918-1921, 2006.

[39] P. K. Wesseh and B. Lin, "Climate change and agriculture under $\mathrm{CO}_{2}$ fertilization effects and farm level adaptation: where do the models meet?" Applied Energy, vol. 195, pp. 556-571, 2017. 